\title{
NOTAS ETNOGRÁFICAS SOBRE A DESIGUALDADE EDUCACIONAL BRASILEIRA
}

\author{
Maria Silvia Pinto de Moura Librandi da Rocha* \\ Graziela Serroni Perosa*
}

\begin{abstract}
RESUMO: Este artigo tem por objetivo compreender as relações entre experiências escolares e a construção de fronteiras sociais, a partir de uma pesquisa de inspiração etnográfica, realizada em duas escolas (uma pública e uma privada), entre os anos de 2006-2007. Tendo como referência o relatório dos resultados do SAEB de 2003 e o que nele se aponta como indicadores de uma "boa escola", procura-se analisar as diferentes possibilidades de construção do chamado "clima escolar", em função da diversidade das condições concretas e objetivas de trabalho com que se defrontam diretores e professores, em cada uma das unidades educacionais pesquisadas. Ao final do artigo, aponta-se para a importância de se considerar a interdependência entre os fatores intra-escolares e extra-escolares para a construção de uma "boa escola", argumentando-se que não fazê-lo acarreta sérios limites aos esforços coletivos para a superação das desigualdades educacionais brasileiras.
\end{abstract}

Palavras-chave: Práticas pedagógicas. Desigualdades educacionais. Clima escolar.

\section{ETHNOGRAPHIC NOTES ABOUT BRAZILIAN EDUCATION INEQUALITY}

ABSTRACT: The aim of this article is to help understand the relations between schooling experiences and the construction of social frontiers. It is based on a study carried out at a public and a private school, be-

\footnotetext{
* Doutora em Educação, professora da Pontifícia Universidade Católica de Campinas (PUC-CAMPINAS) e membro do grupo de pesquisa Qualidade de Ensino do Programa de Pós-graduação em Educação da mesma Universidade.E-mail: silrocha@uol.com.br

** Doutora em Educação e professora da Escola de Artes, Ciências e Humanidades da Universidade de São Paulo (USP).E-mail: grazielaperosa@yahoo.com.br
} 
tween 2006 and 2007. Drawing on the SAEB (Sistema Nacional de Avaliação da Educação Básica, or National System of Basic Education Evaluation) 2003 report and on what it shows as indicators of a "good school", different possibilities of building a "school atmosphere" were analyzed, in relation to the wide range of concrete and objective work conditions that principals and teachers face at each one of the educational units involved in the study. At the end of the article, there is a focus on the importance of considering the interdependence between internal and external factors that influence the construction of a "good school". It is also asserted that overlooking this consideration brings about serious restrictions to overcoming Brazilian educational inequality.

Key words: Pedagogical practices. Educational inequality. School atmosphere.

$E$ ste artigo expóe parte dos resultados de uma pesquisa mais ampla sobre a relação entre educação e classes sociais. ${ }^{1} \mathrm{O}$ objetivo principal foi interrogar a participação das experiências educativas para o fortalecimento, enfraquecimento ou superação das fronteiras sociais que agregam e segregam os indivíduos no interior de uma dada sociedade (Lamont \& Molnar, 2002; Saint-Martin \& Gheorghiu, 2007). Exemplos de fronteiras sociais bem estabelecidas no Brasil dizem respeito diretamente às questôes educacionais, tais como a distância material e simbólica entre letrados e iletrados, entre egressos dos cursos técnicos e dos cursos superiores e, simultaneamente, às dinâmicas de ocupação do espaço urbano e rural e à expansão da escolarização que afetaram, de forma altamente diferenciada, a população brasileira.

Esses complexos processos sociais foram reexaminados a partir dos resultados de uma pesquisa coletiva que entrevistou pais e filhos, entre 12 e 21 anos, de diferentes grupos sociais (27 núcleos familiares e 67 entrevistas) e observou duas escolas, uma pública e outra privada, que recebiam boa parte das famílias entrevistadas, em alguns casos já há duas gerações. São duas escolas de ensino fundamental, estudadas para compreender como se constroem as desigualdades educacionais em um determinado espaço geográfico e de relações sociais. O interesse foi ultrapassar a simples constatação das diferenças e interrogar a gênese das micro-operações que constroem as desigualdades internas ao sistema de ensino brasileiro, bem documentadas pelos resultados de 
exames nacionais e por boa parte da literatura educacional no país. Algumas razões da permanência de algumas dessas diferenças educacionais, a despeito dos investimentos realizados nas últimas décadas tanto em termos financeiros, pelo Estado, quanto em termos políticos e pedagógicos, pelos próprios professores e suas associações de classe, foram capturadas aqui a partir de uma pesquisa de inspiração etnográfica, realizada em dois estabelecimentos de ensino, entre 2006 e 2007.

Os resultados do exame do Sistema de Avaliação do Ensino Básico $(\mathrm{SAEB})^{2}$ mostram que é impossível apreender a dinâmica das desigualdades educacionais, senão de forma comparativa. A oferta escolar no Brasil é extremamente heterogênea e diversos fatores intervêm para definir essa realidade. Às disparidades regionais, sociais e econômicas do país, permanecem sobrepostas desigualdades propriamente escolares. Segundo esses mesmos resultados, sobrevive de forma bastante acentuada a distinção entre as escolas rurais e urbanas. ${ }^{3}$ Um outro vetor que estrutura essas desigualdades de experiência escolar está relacionado à dependência administrativa das escolas. ${ }^{4}$ Parte da literatura sociológica brasileira estuda essas desigualdades e suas relações com as diferenças entre as famílias dos grupos populares e dos grupos médios, descrevendo a variabilidade das estratégias e das formas de se relacionar com a instituição escolar de frações distintas dos grupos sociais (Romanelli, 1997; Nogueira, 1997; Nogueira et al., 2003; Zago, 2006; Vianna, 2005; Thin, 2006). A introdução dos exames e provas de avaliação do ensino básico na década de 1990 disponibilizou dados que vêm alimentando o debate sobre os fatores explicativos das desigualdades educacionais, revigorando a tradição dos surveys no sistema educacional do país (Bonamino et al., 2002; Barbosa, 2007). Entre tais estudos, destacam-se aqueles que buscam conceituar e mensurar o "efeito escola", analisando os resultados obtidos pelos alunos de estabelecimentos de ensino específicos, mas considerando e, inclusive, buscando isolar, por meio de técnicas estatísticas, a influência do nível socioeconômico sobre o desempenho escolar para interrogar-se sobre as condiçôes propriamente escolares que podem ser associadas a melhores desempenhos (Soares \& Andrade, 2006).

A nota oficial que acompanha o SAEB de 2003, ao discutir o que compõe uma "boa" escola no Brasil, apresenta os fatores explicativos das desigualdades educacionais em dois eixos distintos: "O primeiro diz respeito às condições de vida do aluno, de sua família e de seu contexto social, cultural e econômico. $\mathrm{O}$ segundo refere-se à própria escola e pode 
ser descrito por meio dos professores, diretores, projetos pedagógicos, insumos, instalaçôes, estrutura institucional, 'clima' da escola e relações intersubjetivas no cotidiano escolar" (Brasil, 2004).

Os objetivos desse artigo são contribuir para compreender, de forma mais aprofundada, o que se define como "clima" de uma instituição escolar, levantar as razões que ajudam a precisar os modos pelos quais este "clima" se instaura e se mantém e, por fim, identificar relações entre os dois eixos propostos pelo SAEB - os fatores extra-escolares e os intraescolares. Para tal, apresentaremos algumas das diferenças identificadas nas duas escolas pesquisadas e descreveremos as configurações particulares nas quais essas unidades educacionais estão envolvidas e que explicam - ao menos em parte - o "clima" encontrado em cada uma delas. A construção do material empírico foi possível graças a um período de imersão nestes estabelecimentos de ensino, em que foram realizadas observações sistemáticas semanais (registradas em caderno de campo), entrevistas com pais, professores, diretores e alunos (voltadas, portanto, para apreender os diversos pontos de vista sobre a escola e sobre o processo de escolarização) e a consulta aos arquivos escolares (fichas de matrícula, impressos e fotografias). Dispúnhamos, também, dos dados sobre a história dos grupos familiares, a partir do trabalho realizado pela equipe de pesquisa, da qual o material aqui apresentado faz parte. Procuramos, com estes procedimentos metodológicos, ultrapassar os limites das pesquisas baseadas exclusivamente em dados quantitativos, que agregam situações escolares muito diferenciadas, sob a rubrica de sua filiação administrativa comum, por exemplo.

A pesquisa em equipe permitiu atacar uma outra cisão séria na literatura educacional que é a tendência a estudar isoladamente os processos educativos - tomando as diferentes instituições encarregadas da educação das gerações mais novas (a família ou a escola) como esferas autônomas de ação. Numa tentativa de restituir a integridade dos processos educativos em uma única dimensão analítica, mobilizamos procedimentos de pesquisa capazes de aproximações mais refinadas da multiplicidade de agentes de socialização e de suas ações.

Ao pesquisarmos, simultaneamente, uma escola pública e uma privada, pretendemos operacionalizar uma leitura do sistema de ensino brasileiro em sua heterogeneidade e de forma relacional (Bourdieu, 1992). A rigor, essa comparação entre o sistema público e privado é 
realizada diariamente, de forma oficial e não-oficial: está presente nos exames do sistema de ensino, é explorada pela imprensa na divulgação dos rankings entre escolas, circula pelo discurso de pais com filhos em idade escolar e entre os egressos do sistema de ensino. Não há dúvidas sobre a importância desta comparação.

A imensa maioria das crianças brasileiras está matriculada no setor público, que recebe $82 \%$ da população em idade escolar, enquanto apenas $17,4 \%$ freqüentam o ensino fundamental privado. Entretanto, essa minoria numérica torna-se bastante significativa se analisamos os dados relativos a exames de ingresso no ensino superior público brasileiro, cujos diplomas são mais prestigiados (Neves, Raizer \& Fachinetto, 2007). ${ }^{5}$ Esses números expressam, de maneira cabal, a existência de uma unificação formal do sistema de ensino brasileiro e, ao mesmo tempo, a sua profunda segmentação e diferenciação interna que tendem a produzir efeitos de destino sobre a trajetória individual daqueles que passam pelo seu interior, o que significa a quase totalidade da população, no contexto de expansão da escolarização brasileira acentuada nas últimas décadas. $\mathrm{O}$ Brasil procura aprofundar sua experiência democrática moderna e atribui à escola importante papel nesse processo, o que exige uma compreensão acurada das condições objetivas de trabalho com que professores e diretores, pais e alunos são confrontados à frente de uma unidade escolar (Almeida, 2001). São esses indivíduos que concretizam, por meio da interação social e de uma dada configuração das relações sociais (Elias \& Scotson, 2000), o "clima" das escolas.

\section{A cidade e as escolas}

O local escolhido para realizar a pesquisa foi um município (nomeado aqui como Princesa Isabel) que fica ao lado de uma grande cidade do interior paulista. ${ }^{6}$ A região concentra mais de 5\% do PIB nacional de 2007. Em sua origem histórica, a pequena cidade rural, de grandes fazendas de café, dotada de uma estação ferroviária dos anos de 1940/ 1950, viu o "progresso" chegar, sofrendo uma transformação acelerada desde o final dos anos de 1960, resultado da onda de industrialização e de urbanização que o país viveu, em especial o estado de São Paulo. No caso de Princesa Isabel, esta movimentação gerou um processo de diferenciação social progressiva de seus moradores, ${ }^{7}$ ao atrair para lá habitantes da região rural do país - que vieram em busca de melhores condições de vida 
- e profissionais de nível superior - que vieram em função de novas oportunidades de trabalho e de educação trazidas pela instalação de um pólo tecnológico e de uma universidade na cidade. Apesar dessa diferenciação, a população que ali reside não representa os extremos da desigualdade de renda do país, o que nos permitiu minimizar os efeitos da extrema abundância de recursos e/ou da precariedade absoluta deles sobre os processos educativos. Atualmente, o município possui cerca de 40 mil habitantes e 24 estabelecimentos de ensino, que se distinguem em função de sua situação administrativa (pública ou privada) e pelos ciclos de escolarização que oferecem. Dentre estes estabelecimentos, no que se refere ao ensino fundamental, existem no distrito oito escolas estaduais, quatro escolas privadas e uma municipal.

Uma importante clivagem que que separa os estabelecimentos de ensino é dada pela posição social das famílias: as de maior renda e mais escolarizadas encontram-se na rede privada, diferenciadas em termos de estilos pedagógicos, que podem ser mais ou menos "tradicional", segundo as categorias mobilizadas pelos pais e mães entrevistados. As famílias de mais baixa renda e menos escolarizadas estão na rede pública. A presença, em Princesa Isabel, de cinco escolas de línguas estrangeiras, escolas de arte e de música, escolas de práticas esportivas (natação, arte circense, artes marciais, futebol) e estruturas de apoio pedagógico (para crianças com dificuldades escolares), todas elas privadas, é reveladora da lógica de educação dos grupos privilegiados: o "cultivo orquestrado", definido por Lareau (2007, p. 17), que se caracteriza por um trabalho intenso de organizar para as crianças uma agenda com atividades percebidas como forma de transmitir-lhes habilidades importantes para a vida, complementando o trabalho escolar. Há, ainda, estruturas péri-escolares, de origem filantrópica, que oferecem programas educacionais gratuitos para os grupos populares.

Localizadas em dois bairros distintos de Princesa Isabel, as duas escolas focalizadas em nosso estudo foram criadas a partir da mobilização de grupos de famílias moradoras no distrito, na década de 1970. A escola pública (aqui nomeada como Marília Penteado) foi reivindicada ao poder municipal por famílias compostas por trabalhadores manuais e agricultores (pequenos proprietários e/ou assalariados). A reivindicação decorreu do fato de que, a esta época, Princesa Isabel dispunha de apenas duas escolas públicas estaduais, ambas localizadas no centro do município, o que obrigaria as crianças destas famílias a percorrerem a pé uma distância de pelo 
menos $6 \mathrm{~km}$ para chegarem à escola, dado que nenhuma linha de transporte público servia o bairro. A escola privada (aqui nomeada Ypê), por sua vez, foi criada a partir da mobilização de um grupo de famílias que vieram residir em Princesa Isabel na esteira das transformaçōes trazidas pela implantação de uma universidade pública e como conseqüência da industrialização e do desenvolvimento de um pólo tecnológico na região. Estas famílias rejeitavam as escolas públicas e privadas disponíveis à época, em especial, aquelas conhecidas por seu método pedagógico nomeado como "tradicional", consideradas inadequadas para seus filhos. Esse tipo de rejeição não era raro entre os grupos mais escolarizados durante a ditadura militar, para os quais a escola podia ser pensada como um espaço de resistência, um lócus de inovação pedagógica, baseado, sobretudo, na maneira de conceber a autoridade pedagógica. ${ }^{8}$

A possibilidade de pensar a inserção das crianças em um ou outro estabelecimento de ensino como uma escolha, com a qual os grupos mais privilegiados são confrontados, revelou-se, ao longo das entrevistas com as famílias, uma estratégia fortemente ligada aos projetos de reprodução dos grupos familiares em pelo menos duas geraçôes, guiada por um projeto de ascensão social ou por um projeto de consolidação de uma posição social já adquirida (Nogueira, 1998; Almeida \& Nogueira, 2002; Perosa, 2006). Já as famílias dos grupos populares não têm muitas margens para escolhas. Elas estão excluídas das escolas privadas e devem se dirigir às escolas públicas, subordinando-se aos critérios de matrícula baseado na proximidade da moradia com a escola, sobre os quais não têm quase nenhum controle, já que não têm muitas chances de escolha do endereço, em geral circunscrito por necessidades muito concretas, ligadas ao valor dos aluguéis ou terrenos que conseguem adquirir.

\section{Como se define o clima de uma escola?}

Ao indicar as características de uma boa escola, o relatório SAEB-2003 (Brasil, 2004) aponta para a importância de que os alunos sejam conduzidos a um bom relacionamento coletivo, produtivo e prazeroso. Indica-se, ainda, como condição essencial para que isso seja atingido, que os professores acreditem em seus alunos e que sejam colocadas em ação estratégias para a integração efetiva da comunidade ao cotidiano escolar. Entende-se ser responsabilidade direta dos professores e diretores a criação deste bom 
"clima" de relaçôes; no caso destes últimos, cabe-lhes, sobretudo, exercer sua liderança, o que pode ser traduzido pela necessidade de motivar e gerir a comunidade escolar, incluída, aqui, a sua equipe. As possibilidades de construção de relaçóes intersubjetivas que se organizem desta forma estão, sem dúvida, relacionadas a características concretas da estrutura e funcionamento das escolas. Por esta razão, apresentaremos a seguir informaçôes sobre cada uma das instituiçôes escolares estudadas, que nos permitirão ter um panorama mais preciso sobre o solo a partir do qual se fundam as relaçôes que queremos analisar.

\section{Quadro sinóptico I}

\begin{tabular}{|c|c|c|}
\hline & Escola Marília Penteado & Escola Ypê \\
\hline Estatuto & Pública & Privada \\
\hline Data de Fundação & 1978 & 1976 \\
\hline $\begin{array}{l}\text { Número total de } \\
\text { alunos }\end{array}$ & 540 & 170 \\
\hline \multirow[t]{5}{*}{ Equipe escolar } & $\begin{array}{l}\text { Composição: } 1 \text { diretora, } 1 \\
\text { vice-diretora, } 1 \text { orientadora } \\
\text { pedagógica, } 27 \text { professores }\end{array}$ & $\begin{array}{l}\text { Composição: } 1 \text { diretora, } \\
1 \text { orientadora pedagógica, } \\
19 \text { professores }\end{array}$ \\
\hline & $\begin{array}{l}\text { Formação: } \\
\text { Ensino Médio: } 1 \\
\text { Ensino Superior: } 22 \\
\text { Mestrado: } 2 \\
\text { Doutorado: } 2\end{array}$ & $\begin{array}{l}\text { Formação: } \\
\text { Ensino Superior: } 14 \\
\text { Mestrado: } 4 \\
\text { Doutorado: } 1\end{array}$ \\
\hline & $\begin{array}{l}\text { Tempo de magistério na } \\
\text { escola }\end{array}$ & Tempo de magistério na escola \\
\hline & $\begin{array}{l}\text { Estão na escola há mais de } 5 \\
\text { anos: } 77,78 \%\end{array}$ & $\begin{array}{l}\text { Estão na escola há mais de } 5 \\
\text { anos: } 31,57 \%\end{array}$ \\
\hline & Há mais de 11 anos: $48,15 \%$ & Há mais de 11 anos: $26,31 \%$ \\
\hline Ocupação/pais & $\begin{array}{l}\text { Trabalhadores manuais: } \\
\text { pedreiros, pintores, } \\
\text { caminhoneiros; } \\
\text { Operários qualificados em } \\
\text { menor número: eletricista etc. }\end{array}$ & $\begin{array}{l}\text { Professores universitários, } \\
\text { profissionais liberais, altos } \\
\text { funcionários do setor privado, } \\
\text { pequenos comerciantes e } \\
\text { funcionários da UNICAMP. }\end{array}$ \\
\hline
\end{tabular}




\begin{tabular}{|l|l|l|}
\hline Escolaridade/pais & $\begin{array}{l}\text { Ensino fundamental } \\
\text { incompleto } \\
\text { Ensino médio } \\
\text { Ensino superior completo (1) }\end{array}$ & Ensino superior completo \\
\hline Ocupação/mães & $\begin{array}{l}\text { Empregadas domésticas, } \\
\text { cozinheiras, empregadas do } \\
\text { comércio, donas de casa. }\end{array}$ & $\begin{array}{l}\text { Professoras primárias, de } \\
\text { ensino fundamental e de } \\
\text { ensino superior, funcionárias } \\
\text { com ensino superior } \\
\text { (UNICAMP), dona de casa. }\end{array}$ \\
\hline Escolaridade/mães & $\begin{array}{l}\text { Ensino fundamental } \\
\text { incompleto e Ensino médio }\end{array}$ & Ensino superior completo \\
\hline
\end{tabular}

É a partir deste conjunto de aspectos estruturais que operações cotidianas, aparentemente banais, materializam-se. As análises sobre estas operações e sobre as condições que as engendram, relatadas pelos entrevistados e registradas no dia-a-dia escolar, tornam possível a reconstrução e compreensão do "clima" no qual estão assentadas as relações intersubjetivas na escola, com diferenças bastante radicais em um e outro estabelecimento de ensino.

Essas diferenças aparecem em múltiplas dimensões. Se tomarmos como exemplo a relação que a escola estabelece com os alunos e suas famílias, isso se torna bastante visível. Assim, no início do ano letivo, as famílias da escola Marília Penteado recebem um documento denominado "Normas disciplinares de convivência", a partir do qual são informadas sobre: obrigatoriedade de uso do uniforme, horário, responsabilidades dos alunos, regras gerais e penalidades a serem aplicadas no caso de não obediência a estas normas. Além disso, a escola tem modelos de "Advertência oral", "Convocação", "Termo de compromisso para aulas de reforço", todos eles escritos em linguagem bastante formal, com cuidados quase jurídicos. $\mathrm{Na}$ escola Ypê, diferentemente, a primeira comunicação do ano foi uma carta, onde se lia:

Bem-vindos ao novo ano escolar. É um ano de reflexões, de recomeços e de partidas. Conscientes do nosso privilégio de ter conosco pais que apóiam o nosso trabalho, de professores bem preparados e dispostos a arriscar, nós estaremos sempre motivados a continuar com nosso projeto político-pedagógico dessa escola. 
A atmosfera mais impessoal, institucionalizada, com a qual se deparam as famílias e os alunos da Marília Penteado, contrasta com o ambiente "familiar" encontrado na escola Ypê, e é apenas um pequeno exemplo de como as relaçôes entre as escolas, alunos e familiares são construídas, passo a passo. $\mathrm{O}$ quadro a seguir oferece mais informaçōes sobre as diferenças encontradas em cada uma destas realidades educacionais.

O exame do tempo reservado ao recreio, do momento das refeições e das instalaçóes e equipamentos de lazer é bastante revelador do que dispõem cada uma das professoras e diretoras para a construção do

\section{Quadro sinóptico II}

\begin{tabular}{|c|c|c|}
\hline & Escola Marília Penteado & Escola Ypê \\
\hline $\begin{array}{l}\text { Entrada e } \\
\text { saída }\end{array}$ & $\begin{array}{l}\text { - Portão trancado, controlado por } \\
\text { um guarda, que o abre após o sinal. } \\
\text { - Pais não têm contato diário com a } \\
\text { professora. } \\
\text { - Pais e mães não são chamados pelos } \\
\text { nomes, mas genericamente como "pai" } \\
\text { e "mãe". } \\
\text { - Horário rígido, não pode atrasar. } \\
\text { - Em casos de atrasos regulares, ad- } \\
\text { vertência formal. }\end{array}$ & $\begin{array}{l}\text { - Portão aberto, com por- } \\
\text { teiro. } \\
\text { - Pais levam as crianças até } \\
\text { a professora. } \\
\text { - Pais e professoras se cha- } \\
\text { mam pelo nome. } \\
\text { - Tolerância com atrasos } \\
\text { na entrada e saída. } \\
\text { - Em casos de atrasos re- } \\
\text { gulares, conversas com os } \\
\text { pais. }\end{array}$ \\
\hline $\begin{array}{l}\text { Número de } \\
\text { alunos na } 1^{a} \\
\text { série }\end{array}$ & - 28 & - 12 \\
\hline Recreio & - $25^{\prime}$ & - 45 \\
\hline Refeições & - Merenda da escola & - Lanche trazido de casa \\
\hline $\begin{array}{l}\text { Instalações e } \\
\text { Equipamentos } \\
\text { de lazer }\end{array}$ & $\begin{array}{l}\text { - Quadra de esportes } \\
\text { - } 3 \text { playgrounds } \\
\text { - Casinha de bonecas, casinha de } \\
\text { Tarzã } \\
\text { - Escorregadores de diversos tama- } \\
\text { nhos } \\
\text { - Tanques de areia } \\
\text { - Gira-gira } \\
\text { - Pontes de cordas e madeira }\end{array}$ & $\begin{array}{l}\text { - Quadra de esportes } \\
\text { - Existe playground com } \\
\text { escorregador, gira-gira e } \\
\text { gangorra, mas está, geral- } \\
\text { mente, trancado, inacessí- } \\
\text { vel às crianças mesmo du- } \\
\text { rante o horário do recreio. }\end{array}$ \\
\hline
\end{tabular}


“clima” institucional. Na escola Marília Penteado, embora o refeitório esteja instalado em uma sala ampla, com mesas compridas e bancos coletivos, o espaço não comporta todas as turmas juntas e a escola tem que se organizar para oferecer a refeição em horários diferentes para cada série. Assim, o cardápio composto, por exemplo, por "arroz, carne de panela com mandioca e salada de acelga", "arroz, ovos mexidos com ervilha e tomate", "arroz, ovos mexidos e cenoura", "sopa”, embora planejado para o almoço, é servido para as turmas de primeiro ano, a crianças de 6 anos, às 9:15 da manhã. Durante a merenda, a ênfase das prescrições das professoras é para que os alunos "não desperdicem" a comida posta no prato. A situação gera tensões entre os adultos - preocupados em garantir uma boa alimentação - e as crianças - que nem sempre se interessam por esse cardápio e, muitas vezes, comem com evidente desprazer, apenas para atender às suas professoras.

É necessário informar que a organização da merenda nas escolas municipais é terceirizada e controlada por um centro de abastecimento alimentar (CEASA). Sendo assim, a equipe escolar não pode fazer qualquer alteração no cardápio, a não ser que se disponha a enfrentar inúmeras negociações (com a Secretaria de Educação, com o Departamento de Nutrição, com o CEASA), o que transforma qualquer intenção simples de adaptar melhor a comida ao gosto das crianças em uma operação muito mais complexa, desencorajando adaptaçōes que seriam desejáveis para as crianças e para atenuar a tensão entre adultos e alunos no horário das refeiçôes.

Contudo, o que está em jogo, num momento do dia escolar aparentemente tão secundário como a merenda, não é apenas uma questão de dieta balanceada e da quantidade de comida ingerida. As tensóes desse acontecimento cotidiano conduziram a diretora da unidade a fazer um levantamento para averiguar quais eram os hábitos alimentares dos alunos, em suas casas. Elaborou-se, então, um questionário enviado a todos, no qual deveriam descrever seu café da manhã típico (em termos de freqüência e cardápio) e almoço (em termos de freqüência). Das 27 respostas dadas pelos alunos de $1^{\circ}$ ano, $74 \%$ fazem o café da manhã diariamente e $82 \%$ declararam terem almoço em casa. A ausência de café da manhã em $26 \%$ das crianças foi assim justificada por eles: "não dá tempo", "porque não gosto", "porque não tenho fome", "porque não quero". Uma criança respondeu que não toma café da manhã porque "não tem 
nada para comer" e que não almoça porque "mamãe não faz". A equipe da escola tratou os dados recebidos, gerou uma planilha com os resultados distribuídos por séries, em números brutos e com as porcentagens das respostas. Este esforço de tratamento do material nos informa que haveria todas as condiçôes para - sendo consideradas verdadeiras as respostas dadas - concluir-se que as crianças da Marília Penteado, em sua maioria, não passam fome. Ou seja, as informações dadas pelos alunos não dão sustentação para as insistências das professoras e nos permitem apontar que na merenda está em funcionamento uma combinação complexa entre todos os dados de realidade que definem as práticas pedagógicas (as instalações, os recursos disponíveis e as características sociais de adultos e crianças) e as representaçôes que se tem sobre os grupos sociais a quem se endereçam as práticas pedagógicas - nesse caso, crianças pobres. A falta de autonomia da direção e o trâmite burocrático para alterar a comida que se serve, e o fato de que a diretora não possa prescindir do almoço para os maiores, ajudam a entender por que não se repete mais o cardápio preferido das crianças dessa série: "sucrilhos, leite e banana”. Nestes dias, as crianças comem muito mais e, se possível, repetem. Esse momento do cotidiano escolar pode custar caro a todos, gerando situações que caminham no sentido oposto ao da construção de relações interpessoais prazerosas, apontadas como a base de uma relação de aprendizagem produtiva.

$\mathrm{Na}$ escola privada, o tempo destinado ao recreio e à refeição é o dobro daquele reservado aos alunos da escola pública. As crianças trazem os lanches de suas casas, preparados, possivelmente, atendendo às suas preferências de paladar. As crianças escolhem onde irão comer, se com os colegas e a professora sob as árvores, se farão um pic-nic em algum ponto de um dos parques ou se irão compor pequenos subgrupos para comerem juntos. Nesse contexto, a refeição pôde ser descrita pela professora como mais um momento importante de convivência, um recurso pedagógico, por meio do qual se trabalha questões éticas e cívicas como os benefícios do compartilhamento de seus lanches entre si. Não foram registradas preocupaçōes/admoestaçōes da professora em relação à refeição das crianças, a não ser uma supervisão discreta das trocas que fazem e da quantidade de consumo. Quando as crianças não comem todo o lanche trazido, o que sobra é re-colocado nas lancheiras, para que as mães possam acompanhar o consumo efetivado. Terminada a refeição, as crianças podem ir brincar nos playgrounds da escola. 
Como se vê, nessa escola privada, o problema de alimentação de seus alunos simplesmente não é da professora. Ela retorna as "sobras" para que a família se encarregue do controle do que é ou não consumido, protegendo a si mesma e aos seus alunos dos conflitos que a alimentação das crianças costuma gerar na escola pública. Esse exemplo mostra como se destina, na escola Ypê, um lugar privilegiado ao exercício da escolha, que atravessa todas as etapas da refeição: o que vão comer, quanto, onde e com quem. Isso acontece também em outras esferas da ação escolar. Nessa escola, por exemplo, as crianças podem intervir em decisões que, habitualmente, são prerrogativas das autoridades escolares. Segundo a diretora, foram os alunos que reivindicaram a extensão do tempo de recreio, argumentando que o intervalo de 30 minutos, inicialmente proposto pela escola, era insuficiente para comer e brincar. Graças à grande autonomia da direção na definição da rotina escolar das crianças, elas puderam ser atendidas com uma ampliação de 15 minutos.

As professoras Maria Raquel e Elisabeth - ambas com diploma de curso superior obtido em universidades prestigiosas - são responsáveis pelo primeiro ano do ensino fundamental na escola Marília Penteado e na Ypê, respectivamente. Elas são confrontadas com situações bastante distintas não apenas no momento de gerir a alimentação das crianças, mas ao longo da jornada escolar e em todas as práticas pedagógicas que elaboram para seus alunos.

\section{É para sonhar?}

As diferentes práticas de socialização das crianças que registramos nas duas escolas poderiam ser interpretadas, de modo redutor, como exercício sistemático de opressão pura e simples no caso da escola pública. A professora Maria Raquel (escola municipal) tem um salário melhor do que a professora Elizabeth (escola privada), está na escola há mais tempo e tem a estabilidade funcional que sua colega da escola privada não possui, já que o emprego de Elizabeth depende das relações que estabelece com a diretora, com seus alunos e com os pais da escola. Isto significa que, em termos de experiência e inserção profissional na escola, a professora Maria Raquel contaria com a segurança de itens apontados como importantes para a prática pedagógica (Sztajn, Bonamino \& Franco, 2003). Entretanto, consideramos o salário e a estabilidade apenas 
como a ponta mais visível do que se oferece como condições de trabalho para as professoras, e uma análise mais refinada sobre o que elas dizem a respeito de seu exercício profissional expõe elementos importantes para avaliarmos a complexidade da trama em que se envolvem as açóes pedagógicas e as tomadas de decisão que as professoras e a escola devem assumir em seu trabalho diário.

Ao falar sobre os recursos materiais disponíveis para as crianças brincarem na escola - uma das atividades mais enfatizadas pelos documentos orientadores para as práticas pedagógicas no primeiro ano do novo sistema de ensino fundamental (Brasil, 2006) -, a professora Maria Raquel lamenta o limite de espaço e a precariedade dos equipamentos.

[Tem] gira-gira, que é perigoso. Desde a primeira semana, já ficou em péssimas condiçôes. No primeiro mês já estava tudo solto. É um gira-gira que as crianças maiores, que também querem brincar e muito, porque também não tem nada de lúdico, não tem uma praça bonita no bairro, não tem nada para eles... Então, eles sentam na roda e se eles inclinam muito a cabeça, pode bater na parede, no muro. $\mathrm{O}$ anjinho aqui é forte! O escorregador é frágil!! Gangorrinha? Simpática, mas é para bebê. Porque: deste tamanhico!.

Tem um pebolim aqui, mas para a gente é mais pesadelo do que solução... Porque não tem espaço para brincar. É muito barulho. Pebolim é associado com barulho, né? Grito, soco, atrapalha as aulas. Porque a acústica nossa também é muito ruim.

Suas preocupações possuem uma justificativa bastante lógica: quando os alunos se machucam, há um ônus grande para as famílias que têm pouquíssimos recursos financeiros para cuidar adequadamente das crianças. Este quadro gera um duplo efeito sobre a professora Maria Raquel: ao mesmo tempo em que se preocupa e se sensibiliza com as grandes dificuldades que serão enfrentadas pelas crianças e seus pais, caso as primeiras se firam, preocupa-se e procura proteger-se das fortes reações das mães que, nestes casos, tendem a culpabilizar a escola e a professora, incluindo, por vezes, ameaças de processos judiciais.

A escola não tem espaço e é muito cimento, muita rampa, muita escada. Então, a gente fica tolhendo a criança o tempo todo. E a gente tolhe porque... Olha, eu estou aqui há 18 anos, eu já vi coisas horríveis acontecerem. Desde uma aluna que subiu na trave. Sabe aqueles ganchinhos? A menina subiu, estava de sandalinha, rasgou o pé. Ficou mais de um mês... A mãe reclamava do 
dinheiro que gastou no antibiótico, porque não sarava o pezinho da menina (...). Então, sabendo disso, a gente fica em cima. Mas é mais questão de preservá-los. A gente gosta muito daqui, mas não tem ambiente adequado.

Ao falar sobre seu trabalho, Maria Raquel enfatiza que parte dos limites vividos e que dificultam o desenvolvimento de práticas pedagógicas diferenciadas deriva do fato de que a sala não é "só dela". A disposição das carteiras em fileiras, modo mais comum de os alunos ocuparem o espaço, por exemplo, não foi apresentada como preferência sua. Ocorre que a sala é ocupada no turno seguinte por uma turma de $8^{\text {a }}$ série e, caso mude a forma de organização do mobiliário, favorecendo o trabalho em grupos, terá que voltá-la ao modo tradicional, antes do término da aula. Estas operações não são simples, consomem muito tempo, produzem barulho e agitam as crianças. Além disso, as carteiras são de tamanho próprio para os alunos de $8^{\mathrm{a}}$ série (em média, de 14 anos), sendo, então, muito altas para as crianças de primeiro ano (em média de 6 anos de idade), o que faz com que muitas delas acabem preferindo ajoelhar nas cadeiras ou ficar de pé para fazer suas atividades, a fim de alcançar melhor as suas mesas. A professora procura insistir para que se sentem de "modo adequado", mas o faz sem muita esperança e com certo constrangimento, porque percebe o desconforto físico que é imposto às crianças. A distribuição dos alunos pelos lugares indicados pela professora, limitando suas possibilidades de escolha, o que poderia ser interpretado como inadequado excesso de autoridade, é, na realidade, uma estratégia usada para tentar atenuar a inadequação do mobiliário, indicando aos menores que se sentem nas poucas carteiras um pouco menos altas que ali estão colocadas.

É certo, entretanto, que estas características da sala de aula e do mobiliário não explicam todas as formas pelas quais Maria Raquel organiza a sala e constrói o "clima" de sua turma, já que, em alguns dias, as carteiras são colocadas em forma de "U”, com algumas dispostas no centro deste "U", que serão ocupadas pelos alunos indisciplinados e pelos mais "atrasados". Embora a professora procure justificar esta prática alegando que, em função do número de alunos em sala de aula, por meio desta estratégia, ela consegue dar atenção mais individualizada aos que mais precisam, não há dúvidas de que, desta forma, a professora lembra a todos a hierarquia simbólica da classe, estabelecida por inúmeras micro-operações de diferenciação, dentre as quais a mais comum é a 
designação dos mais atrasados e dos mais avançados, neste caso, materializada pela separação física de uns em relação a outros.

$\mathrm{Na}$ sala de aula da escola privada, as mesas e cadeiras são do tamanho adequado para a idade das crianças e arrumadas para permitir o trabalho em grupos; os 12 alunos desta turma de $1^{\circ}$ ano podem escolher onde se sentar ou mesmo optar por sentarem-se num tapete com almofadas ou no chão. A professora tem uma mesa para si, embora normalmente se sente junto com as crianças, numa das cadeirinhas perto das mesas. A sua classe não é usada no outro período. Ela pode, então, deixar os materiais pedagógicos adequadamente acessíveis para sua turma, o que lhes possibilita várias escolhas durante a jornada escolar. Pode expor os trabalhos das crianças, fazendo das paredes da sala de aula um espaço de legitimação da importância daquilo que os alunos produzem. Elizabeth também distingue os alunos mais adiantados e os mais atrasados. No vocabulário dessa professora, eles são descritos como estando em "níveis cognitivos diferentes", e em suas estratégias para lidar com estas diferenças ela faz investimentos para atenuá-las:

É uma coisa conversada. Tem criança que se frustra por ver que o outro consegue muito mais... Então é assim: [Eu explico para meus alunos que] ele consegue, mas ele também consegue ir te ajudando. Antes ele também não conseguia. Ele precisou de ajuda para chegar onde ele está. Então, tem esta coisa de estar ajudando para não supervalorizar um e menosprezar outro. E aí, vai na boa. Eles se ajudam, são super adequados. Uns falam como eu: O que você acha que é? Escuta o som. É muito legal.

Nota-se, assim, um esforço para apagar as marcas da hierarquia simbólica que diferencia os alunos no interior desta sala de aula, o que contribui para a criação de um "clima" mais familiar e suave, menos tenso e menos institucionalizado do que na unidade pública. Compartilhar a sala de aula com alunos de outras faixas etárias não é um fato sem importância, como pode parecer aos gestores públicos, sobretudo, quando isso é feito com turmas de crianças de diferentes faixas etárias. Além do que já foi apontado, partilhar a sala de aula com crianças maiores inviabiliza, na prática, que as atividades dos alunos possam ser expostas nas paredes, como a professora Maria Raquel diz que gostaria de fazer. Os colegas da $8^{a}$ série não são nada solidários com as produções das crianças menores: rasgam-nas, escrevem palavrões, ridicularizam os desenhos fazendo, segundo relata Maria Raquel, "bigode em 
carinha de menina". Tendo estas informaçôes em perspectiva, é possível compreender melhor o seguinte excerto, em que são abordadas as condiçôes materiais para o trabalho.

Silvia: E em termos de recursos, Maria Raquel, o que você acha que faz falta? Maria Raquel: Eu queria uma sala só para mim... É para sonhar, né?

Silvia: Lógico (rimos).

Maria Raquel: Uma sala ampla em que a gente pudesse deixar um terrarium montado. Eu já tentei montar terrarium nesta escola duas ou três vezes. Olha, só deu errado, porque a turma da tarde ou colocava água em excesso... Ou então, eles perfuravam o plástico de cima e ai deixa de ser um terrarium... Uma vez eu cheguei aqui, tinha minhoca até pelo alto das paredes...

As insatisfaçōes de Maria Raquel poderiam nos levar a crer que esta professora atribui as razóes dos limites em seu trabalho somente a causas externas, fora de seu controle, desresponsabilizando-se, portanto, das questôes críticas em relação às práticas pedagógicas que coloca em ação. As reflexôes que faz, entretanto, vão além de suas queixas sobre estes limites e estendem-se a si própria:

Eu acho que muito material a gente tem tido, mas... Talvez eu não tenha explorado tanto quanto precisa. Trabalhar com tinta para pintar com os dedos, com as mãos, para depois chegar lá numa coisa mais fina, no pincel. Eu acho que eu trabalho pouco com isso. Eu trabalho pouco. A diretora comprou para nós. Mas, sabe quando tá assim impregnado na cabeça trabalhar com pouco material, para economizar material! Então, quando eu vejo, lá no canto da minha sala, "nossa, tem tanto material, eu preciso trabalhar com isso aqui”. É uma falha minha, mas que já consolidou.

Os 27 anos de experiência em sala de aula, sempre em escola pública, representam para ela "uma luta enorme", durante a qual às exigências de economia de material somou-se a necessidade de assumir "as séries que sobravam", "que ninguém queria" e de "dobrar período", o que define como um verdadeiro "pesadelo na vida de um trabalhador”. Diz a professora Maria Raquel sobre sua trajetória profissional que "foi tão espinhoso, tudo isso". No caso em questão, temos que indagar também até que ponto a ausência de um mobiliário adequado para a escrita e para o exercício do desenho, assim como a ausência de um espaço de recreação adequado, pode contribuir para manter viva 
na memória desta professora a escassez de recursos que pautou sua atuação profissional por tanto tempo.

Marcas bastante diferentes foram sendo deixadas na professora Elizabeth. Trabalhando ao longo de 18 anos, sempre em escolas particulares, chegou também a "dobrar período", mas abriu mão desta estratégia e optou, há 7 anos, por trabalhar apenas na Ypê, em razão do que nomeia como "profunda identificação com o projeto pedagógico e com a equipe" em que se insere. Ela nos diz que procura garantir a seus alunos que aproveitem a riqueza de materiais que a escola disponibiliza, que não são luxuosos, mas diversificados e promissores para o "desenvolvimento de um trabalho criativo". Os 15 anos de participação na escola representam para Elizabeth a possibilidade de enfrentar sempre novos desafios, o que ela avalia como algo bastante positivo para seu crescimento profissional.

Elizabeth: Eu comecei este semestre muito motivada. Acho que eu estou com um grupo muito gostoso...

Silvia: Quais são suas metas com eles? O que você espera para este ano de trabalho com as crianças?

Elizabeth: O que eu pretendo? Acho que eu pretendo curtir esta última infância deles... Não última infância, claro que não, mas curtir o máximo que eu puder estas brincadeiras todas com eles, curtir antes de passar para uma coisa mais sistematizada... Por outro lado, eu acho que eu estou oferecendo alguns recursos para eles se prepararem para esta organizaçāo... A única coisa que eu não gostaria que acontecesse com eles é que se tornassem crianças entediadas... Aquele tédio... Porque eu acho assim, a criança estando feliz está tudo certo.

A menção à equipe escolar nos remete aos pontos finais de diferenciação entre as duas escolas. A diretora de escola privada, por ser sua proprietária, possui autonomia bastante ampla para montar e modificar sua equipe, embora isso não signifique que não haja problemas a serem enfrentados: "A gente não conseguiu segurar pessoas, teve gente muito boa que passou (...), mas aí a escola não teve estofo para pagar um salário condizente com o naipe da pessoa. A gente perde. A gente forma, forma, a pessoa vai embora. Nós nunca conseguimos segurar".

Apesar das dificuldades para manter a equipe do modo estável por muito tempo, a diretora consegue atrair um professorado perfeitamente ajustado ao seu público, montando um grupo de profissionais 
formado por alunos de pós-graduação e graduação das universidades próximas. Ela escolhe com quem vai trabalhar, o que pode passar por critérios bastante objetivos (como o diploma e a experiência anterior etc.), mas passa, igualmente, por afinidades pessoais, de estilo de vida etc., não só entre os profissionais da escola e a diretora, como também entre a equipe escolar e as famílias dos alunos matriculados na escola Ypê. Em grande medida, é por isso que nessa escola o clima de integração entre família e equipe escolar pode ser percebido como um vínculo entre pais e professores, diretora e professores, que se evidencia também nos esforços para uma convivência freqüente. Pais, professoras, diretora, coordenadora pedagógica, por pertencerem a grupos socioeconômicos próximos e possuírem nível educacional também similar, costumam compartilhar um estilo de vida, valores e estratégias de socialização. Contrastam muito com essa integração os modos como são instauradas as relações entre os membros da equipe escolar e entre esta e a comunidade, no caso da escola pública. Primeiramente, porque entre a lógica escolar e as lógicas de socialização dos pais de grupos populares costumam existir importantes disparidades e confrontos (por vezes, antagonismos). No caso em questão, por exemplo, a escolaridade dos pais dos alunos dessa instituição pública foi marcada pelo ingresso tardio na escola, já que boa parte deles vivia em regiōes rurais e de pobreza, o que impõe a entrada precoce no trabalho e, nos casos daqueles que conseguiram prosseguir a escolarização, apesar das adversidades, isso foi alcançado após uma história escolar caracterizada por sucessivas interrupçôes. Com poucos recursos educacionais, eles incentivam suas crianças a investirem no trabalho escolar, como atestaram as entrevistas. Todavia, a relação com a escola tende a ser ambígua e marcada por uma enorme idealização ("dar a eles as chances que eu não tive"), ou desconfiada e mesmo reticente ("a escola não serve para nada, tudo que Adriana aprendeu foi lendo"), conforme nos disseram mães da escola pública, por nós entrevistadas. Nesse caso, a escola, por vezes, é percebida como uma instituição que oferece poucos recursos operatórios para sair da condição de precariedade material que caracteriza essas famílias. Como a escola ocupa posição de hegemonia e seus profissionais ocupam posição de autoridades pedagógicas, dadas as desigualdades de nível educacional e de grupos sociais a que pertencem, é comum que as famílias sintam-se constrangidas e muito pouco à vontade nos contatos com o estabelecimento escolar, como foi relatado no depoimento de algumas das mães. 
As dificuldades nas relações intersubjetivas - inclusive nas que se dão no âmbito exclusivamente escolar - podem advir também de outras esferas. É preciso lembrar que na rede municipal a equipe não é montada pela direção, pois são os professores que escolhem as unidades em que querem trabalhar, ${ }^{9}$ depois de aprovados em concursos públicos e, portanto, impessoais. Isso, certamente, torna maiores os desafios a serem enfrentados pelos diretores de escolas públicas para transformarem um conjunto mais heterogêneo de profissionais em uma equipe integrada, capaz de falar a mesma língua e estabelecer acordos no que tange à suas práticas pedagógicas.

\section{Considerações finais}

Exercer a liderança ou criar um clima e uma atmosfera favoráveis à aprendizagem na escola não depende apenas das características individuais dos professores e de diretores à frente de determinados estabelecimentos de ensino. Procuramos evidenciar, com este artigo, que as condições para que isso aconteça vão além de um salário bom e da estabilidade do cargo. Tanto um quanto o outro são condições indispensáveis e foram resultados das lutas legítimas do magistério público brasileiro, historicamente confrontado com situações adversas e significaram enormes avanços na gestão do sistema de ensino brasileiro. No entanto, analisando os resultados obtidos por meio de nossas observaçóes e entrevistas, nota-se como as questôes de salário e estabilidade não podem ser desvinculadas das questões relacionadas aos modos de recrutamento e às condiçôes de exercício da profissão. Essas condiçôes objetivas contribuem fortemente para instaurar e propiciar o clima e as características das relações intersubjetivas no cotidiano escolar. Buscamos, assim, evidenciar como os dois eixos apontados pelo SAEB-2003 (referentes aos aspectos extra-escolares e intra-escolares) para discutir os fatores que levam à "boa" escola são absolutamente interdependentes e apontar que o desconhecimento dessa interdependência está na origem de políticas públicas, com poucas chances de produzir os resultados desejados. De nossa perspectiva, mesmo que a separação entre os eixos seja apenas para fins analíticos, ela dá margens para nos fazer esquecer as várias formas pelas quais eles se interpenetram. Qualquer política pública que busque intervir em um deles, sem considerar a configuração dessa interdependência - na qual professores, diretores, pais e crianças estão inseridos -, está fadada ao fracasso. 
Em outras palavras, estamos assumindo que não é suficiente, para o Brasil, sair dos patamares em que se encontra no que tange às desigualdades educacionais, elaborar ações voltadas para o combate à pobreza, de um lado, e à melhoria da escola pública, de outro. No que tange à superação das desigualdades educacionais brasileiras, dada a heterogeneidade social de sua população (com níveis de escolaridade e renda altamente desiguais), as políticas públicas precisam considerar as configurações específicas em que cada unidade escolar se encontra, para formular programas mais focalizados, que respondam de maneira mais sintonizada às necessidades particulares de cada uma delas. No caso da Marília Penteado, por exemplo, o aumento do número de funcionários que garantisse de forma mais cuidadosa a preservação física das crianças, o atendimento aos pais e o auxílio à professora em tarefas rotineiras, bem como a adequação do mobiliário, a disponibilização de equipamentos de parque de qualidade seriam açóes altamente desejáveis e, seguramente, atenuariam as situações de tensão que foram registradas ao longo da pesquisa. É importante destacar que os diversos cadeados usados pela escola (no portão de entrada, no parque, na sala de aula) são função direta destas condições de infra-estrutura e, ao mesmo tempo, simbolizam a pouca disponibilidade da/na instituição educacional para a integração mais efetiva com seus usuários. Convém, ainda, lembrar que a utilização de espaços e equipamentos da escola pela comunidade e pelas famílias dos alunos (dentre os quais, as quadras esportivas e a biblioteca escolar são consideradas pontos nucleares), estratégia fundamental para a construção de um clima positivo de relações entre estas diferentes instâncias de socialização, não pode ser colocada em funcionamento por um mero decreto dos gestores. Especialmente quando se trata de trazer para perto uma população com histórica relação de distanciamento e estranhamento do universo escolar, estas ações requerem um projeto que conte com os recursos necessários para sua efetivação, a fim de apoiar a construção de um novo modo de conceber a escola e de ampliação da integração dos espaços de socialização.

Foge do escopo desse artigo explorar todas as possibilidades de formulação de programas e políticas adequadas para uma e outra realidade. Contudo, cabe sublinhar que eles devem ser pensados necessariamente a partir de um diagnóstico sobre a quem as práticas pedagógicas se destinam, por quem elas são efetivamente postas em ação e com que recursos. Não se trata de sugerir que cada escola seja estudada em 
profundidade antes de ser objeto de uma política pública, o que evidentemente seria inviável. Trata-se de aliar a base de dados estatísticos produzidos na década de 1990, a dos exames nacionais, às pesquisas qualitativas que possam evidenciar as razões mais complexas ou, por vezes, mais prosaicas que terminam por contribuir para a determinação do "clima” de uma instituição escolar, que não se constrói em um vácuo social, mas é o resultado das interações entre indivíduos localizados em configurações sociais específicas.

\section{Recebido em maio de 2008 e aprovado em julho de 2008.}

\section{Notas}

1. A pesquisa "Education et production des frontières sociales" foi dirigida por Monique de Saint Martin, da Ecole des Hautes Etudes en Sciences Sociales (Paris), a partir do auxílio financeiro do Ministère Delegue à la Recherche (França).

2. Os exames nacionais foram implementados no inicio da década de 1990 no Brasil. Estamos nos baseando em resultados apresentados na série histórica do SAEB (1995-2005) e na avaliação que se fez dos resultados obtidos com o SAEB de 2003 (Brasil, 2004).

3. De forma independente de sua filiação administrativa, as escolas urbanas possuem taxas muito superiores de desempenho escolar quando comparadas às escolas rurais. A média nacional dos alunos de $4^{\mathrm{a}}$ série do ensino fundamental das escolas urbanas é de 175,5 e entre as escolas rurais a média cai para 148,3 (Brasil, 2005).

4. A importância da dependência administrativa na definição dos resultados escolares dos alunos pode ser observada nos resultados de exames escolares. Por exemplo, a média nacional do desempenho na disciplina de português para os alunos de $4^{a}$ série do ensino fundamental entre escolas do estado e da rede privada é de, respectivamente, 181,8 e 211,6 (Brasil, 2005, p. 12-15).

5. Uma clara inversão se observa: $73,2 \%$ dos matriculados cursaram o ensino médio exclusivamente na escola privada e apenas $21,2 \%$ o fizeram integralmente em escolas públicas. Um bom exemplo é vestibular da FUVEST que seleciona os estudantes para a USP, no qual se nota que, em relação à origem dos alunos por dependência administrativa da escola do ensino fundamental, a situação é um pouco melhor: aqueles que realizaram o ensino fundamental apenas na escola pública representam $46,6 \%$ e apenas $38,4 \%$ dos aprovados no exame fizeram o ensino fundamental em escolas privadas. Entretanto, como se sabe, a variação por carreiras da universidade é enorme, de novo, quando examinamos os dados de carreiras mais concorridas (algumas engenharias, medicina, odontologia, entre outras), os egressos do ensino fundamental privado voltam a representar cerca de $70 \%$ dos aprovados. Fonte: Estatísticas sobre o vestibular da FUVEST (2006), disponível em: <www.fuvest.br>.

6. Princesa Isabel está localizada ao lado de um município maior do interior paulista com população estimada de 1.039.297 pessoas. Fonte: IBGE (2000).

7. A população de Princesa Isabel passou de 8.204 pessoas em 1970 para 19.224 em 1980, 40.020 em 1981 e, finalmente, 45.585 em 2000, ano do último recenseamento. Fonte: IBGE (2000). 
8. Essa configuração específica levou à criação de diversas escolas "alternativas" no país, organizadas como escolas "democráticas", nas quais os professores e os alunos detinham mais poder sobre a definição do trabalho pedagógico e das regras disciplinares. Para compreender a geração das "escolas alternativas" criadas na década de 1970, é preciso lembrar a figura quase mítica do educador Paulo Freire, que desenvolveu um método para a alfabetização de adultos opondo-se ao método dito tradicional, baseado na repetição de palavras e frases que ele acreditava serem desprovidas de sentido para os alunos dos grupos populares. Freire se tornou um ícone da resistência ao regime militar implantado no Brasil em 1964 e mundialmente conhecido por seu engajamento em uma educação popular capaz de libertar os brasileiros não letrados de sua "alienação", produzindo, por meio da relação com a leitura e a escrita, uma "tomada de consciência" de sua condição de oprimidos. Sua militância na educação popular inspirou também um movimento pedagógico de oposição ao ensino tradicional, em parte das escolas privadas.

9. Dentre as razōes para a escolha dos docentes de uma escola, predominam critérios de ordem prática ou mesmo de julgamento associados às possíveis qualidades ou fragilidades do público que a escola recebe.

\section{Referências}

ALMEIDA, A.M.F.; NOGUEIRA, M.A. (Org.). A escolarização das elites. 2. ed. Petrópolis: Vozes, 2002.

ALMEIDA, A.M.F. The formation of the elites in São Paulo, Brazil. Social Science Information sur les Sciences Sociales, Paris, v. 40, n. 4, p. 585-606, 2001.

BARBOSA, M.L.O. As desigualdades diante da educação e seus efeitos sociais - Introdução. Cadernos do CRH, Salvador, v. 20, p. 9-13, 2007.

BONAMINO, A.M.C.; FRANCO, C.; COSCARELLI, C. Avaliação e letramento: concepçóes de aluno letrado, subjacentes ao SAEB e ao PISA. Educação \& Sociedade, Campinas, v. 23, n. 81, p. 91-113, 2002.

BOURDIEU, P. O poder simbólico. Rio de Janeiro: Bertrand Brasil, 1992.

BRASIL. Ministério da Educação/INEP. Resultados do SAEB 2003. (Versão preliminar). Brasília, DF, jun. 2004.

BRASIL. Ministério da Educação/INEP. Médias do desempenho do SAEB/2005 em perspectiva comparada. Brasília, DF, fev. 2005.

BRASIL. Ministério da Educação. Secretaria de Educação Básica. Ensino fundamental de nove anos: orientaçôes para a inclusão da criança de seis anos de idade. Brasília, DF, 2006.

Educ. Soc., Campinas, vol. 29, n. 103, p. 425-449, maio/ago. 2008 
ELIAS, N.; SCOTSON, J.L. Os estabelecidos e os outsiders. Rio de Janeiro: Zahar, 2000.

LAMONT, M.; MOLNAR, V. The study of bounderies in the Social Sciences. Annual Review of Sociology, Palo Alto, n. 28, p. 167-195, 2002.

LAREAU, A. A desigualdade invisível: o papel da classe social na criação dos filhos em famílias negras e brancas. Educação em Revista, Belo Horizonte, n. 46, p. 13-82. dez. 2007.

NEVES, C.E.B.; RAIZER, L.; FACHINETTO, R.F. Acesso, expansão e eqüidade na educação superior: novos desafios para a política educacional brasileira. Sociologias, Porto Alegre, v. 17, p. 124-157, 2007.

NOGUEIRA, M.A. Convertidos e oblatos - um exame da relação de classes médias/escola na obra de Pierre Bourdieu. Educação, Sociedade \& Culturas, Porto, v. 1, n. 7, p. 109-129, 1997.

NOGUEIRA, M.A. A escolha do estabelecimento de ensino pelas famílias: a ação discreta da riqueza cultural. Revista Brasileira de Educação, São Paulo, v. 1, n. 7, p. 42-561, 1998.

NOGUEIRA, M.A.; ROMANELLI, G.; ZAGO, N. (Org.). Família e escola: trajetórias de escolarização em camadas médias e populares. Petrópolis: Vozes, 2003.

PEROSA, G.S. A aprendizagem das diferenças sociais: classe, gênero e corpo em uma escola para meninas. Cadernos Pagu, Campinas, v. 26, p. 87-111, 2006. (no prelo).

ROMANELLI, G. O significado da educação superior para duas geraçōes de famílias de camadas médias. Revista Brasileira de Estudos Pedagógicos, Brasília, DF, v. 76, n. 184, p. 445-476, 1997.

SAINT-MARTIN, M.; GHEORGHIU, M. (Org.). Education et production des frontiéres sociales: familles, monde associatif et instituitions scolaires. Relatório Final de Pesquisa, Paris, nov. 2007. 235p.

SOARES, J.F.; ANDRADE, R.J. Nível socioeconômico, qualidade e eqüidade das escolas de Belo Horizonte. Ensaio: Avaliação e Políticas 
Públicas em Educação, Rio de Janeiro, v. 14, n. 50, p. 107-126, 2006.

SZTAJN, P.; BONAMINO, A.; FRANCO, C. Formação docente nos surveys de avaliação educacional. Cadernos de Pesquisa, São Paulo, n. 118, p. 11-39, mar. 2003.

THIN, D. Para uma análise das relações entre famílias populares e escola: confrontação entre lógicas socializadoras. Revista Brasileira de Educação, Rio de Janeiro, v. 11, n. 32, maio-ago. 2006.

VIANNA, M.J.B. As práticas socializadoras familiares como lócus de constituição de disposiçôes facilitadoras de longevidade escolar em meios populares. Educação \& Sociedade, Campinas, v. 26, n. 90, p. 107-125, jan./abr. 2005.

ZAGO, N. Do acesso à permanência no ensino superior: percursos de estudantes universitários de camadas populares. Revista Brasileira de Educação, Rio de Janeiro, v. 11, n. 32, p. 226-237, mai-ago. 2006. 